\title{
The Articulated Learning: An Approach to Guided Reflection and Assessment
}

\author{
Sarah L. Ash and Patti H. Clayton
}

\begin{abstract}
The value of reflection on experience to enhance learning has been advanced for decades; however, it remains difficult to apply in practice. This paper describes a reflection model that pushes students beyond superficial interpretations of complex issues and facilitates academic mastery, personal growth, civic engagement, critical thinking, and the meaningful demonstration of learning. Although developed in a service-learning program, its general features can support reflection on a range of experiences. It is accessible to both students and instructors, regardless of discipline; and it generates written products that can be used for formative and summative assessment of student learning.
\end{abstract}

KEY WORDS: reflection; service-learning; assessment.

The value of reflection on experience as a way to enhance learning has been advanced for decades. Over seventy years ago,Dewey (1910) described reflective thought as "active, persistent and careful consideration of any belief or supposed form of knowledge in the light of the grounds that support it, and the further conclusions to which it tends" (p. 6). Schön (1983) saw reflection as "a continual interweaving of thinking and doing" (p. 281); and he described the "reflective practitioner" as one who "reflects on the understandings which have been implicit in [one's] action, which [one] surfaces, criticizes, restructures, and embodies in further action" (p. 50). In a review of the reflection models that have been described over the years, Rogers (2001) found the most common definition of reflection as a process that allows the learner to "integrate the understanding gained into one's experience in order to enable better choices or actions in the future as well as enhance one's overall effectiveness" (p. 41). As Rogers pointed out, however, reflection remains a challenging concept for educators to apply in practice in spite of the potential for positive outcomes.

Sarah L. Ash, Ph.D., received her doctorate in nutrition from Tufts University and is an Associate Professor in the Departments of Animal Science and Family and Consumer Sciences at North Carolina State University. Special interests include the use of critical thinking standards and the reflective processes of service-learning to improve student learning. Patti H. Clayton, Ph.D., received her interdisciplinary doctorate from the University of North Carolina-Chapel Hill and is Coordinator of the NC State ServiceLearning Program in the Faculty Center for Teaching and Learning. She is particularly interested in leadership development through reflection and civic engagement. 
This challenge stems in part from the lack of effective structures to help instructors from diverse disciplines guide students through reflection and meaningful strategies to evaluate the learning outcomes expressed in written products of reflection. Welch (1999) pointed out that it is not enough to tell students to "go and reflect." They need help with connecting their experiences to course material, with challenging their beliefs and assumptions, and with deepening their learning. And it is also not enough to rely on students' testimonials and self-reports to assess the quality of their learning and the meeting of learning objectives. Eyler (2000) suggested that self-reporting leads to a confusion between student satisfaction and student learning, and she called for the development of mechanisms that support students in demonstrating concrete learning outcomes: "What is needed are measures that allow students to show us, rather than tell us, that they have attained greater understanding, ability to apply their knowledge, problem-solving skills and cognitive development" (p. 11).

Faculty and students associated with our service-learning program at North Carolina State University have developed a reflection model that addresses these concerns. In this article we describe first the important, but sometimes unfulfilled, role that reflection plays in service-learning. Next we outline the framework we have developed to guide reflection, followed by a description of the challenges associated with deepening the students' learning from that process and how we have adjusted our approach accordingly to move them to more critical and higher levels of thinking. Finally we discuss its benefits for faculty professional development and ways in which it might be used as a research tool to investigate the relationships between reflection and learning. Although the model we describe has been used most extensively in the servicelearning program, it has the potential to be applied to any pedagogy in which individuals are asked to learn through reflection on experience; and it is based on Bloom's Taxonomy (Bloom, 1956) and standards of critical thinking (Paul, 1993).

\section{Service-Learning as a Model for Reflection}

Service-learning, a form of experiential education, is a collaborative teaching and learning strategy designed to promote academic enhancement, personal growth, and civic engagement. Students render meaningful service in community settings that provide experiences related to academic material. Through guided reflection, students examine their experiences critically, thus enhancing the quality of both their learning and their service. Reviewing approaches to service-learning, 
Eyler, Giles and Schmiede (1996) concluded that reflection is the necessary link that integrates service and learning into a mutually reinforcing relationship. In fact as they point out, "It is critical reflection ... that provides the transformative link between the action of serving and the ideas and understanding of learning" (p. 14). Given the centrality of reflection in service-learning, it is an excellent pedagogy with which to model refinements of reflective processes.

\section{Risks of Poor Quality Reflection}

The ultimate goal of reflection in service-learning is to help students explore and express what they are learning through their service experiences so that both the learning and the service are enhanced. However, developing ways to achieve and demonstrate high quality reflection has been of concern to educators in the service-learning community for some time (Eyler, 2000; Steinke \& Buresh, 2002). As noted by Stanton (1990), when reflection on service is weak, students' learning may be "haphazard, accidental, and superficial" (p. 185). Their learning outcomes are likely to be described vaguely with phrases such as, "I learned a lot," or "I got so much out of my experience." Not only may students learn little or be unable to express articulately the substance of their learning, they may learn the wrong thing. Conrad and Hedin (1990) reminded us of Mark Twain's cat who "learned from sitting on a hot stove lid never to sit again" (p. 87). As with other forms of experiential learning, service-learning frequently puts students in close contact with people or organizations unfamiliar to them but about whom they may have preconceived and unfounded attitudes or beliefs. In theory, such interactions should create precisely the "perplexity, hesitation, doubt" that Dewey (1910, p. 9) saw as key to learning from experience. If students, however, bring their assumptions unchallenged to their reflection on those experiences, they not only close the door to potentially powerful new perspectives, they also allow those experiences to reinforce their stereotypes and prejudices (Hondagneu-Sotelo \& Raskoff, 1994). For service-learning in particular, such simplicity in analyzing complex social conditions can result in students supporting the status quo, rather than being the effective agents of change that service-learning proponents hope to help mold (Strand, 1999).

\section{Outcomes of Rigorous Reflection}

Eyler and Giles (1999) have found in their research that the more rigorous the reflection in service-learning, the better the learning out- 
comes. In extensive interviews with students taking service-learning enhanced classes across the country, the investigators found that quantity and quality of reflection were modest but significant predictors of almost all of the outcomes examined except interpersonal development (leadership, communication skills, working well with others). In particular, they were associated with academic learning outcomes, including deeper understanding and better application of subject matter and increased complexity of problem and solution analysis. They were also predictors of openness to new ideas, problem-solving and critical thinking skills. Overall, their research showed that challenging reflection helped to push students to think in new ways and develop alternative explanations for experiences and observations.

Our approach to reflection more clearly demonstrates rather than reports learning; pushes students beyond superficial interpretations of complex issues; and facilitates academic mastery, personal growth, civic engagement and critical thinking. Our experience suggests that this process is valuable in supporting reflection on a range of experiences, including but not limited to service. It is accessible to both students and instructors, regardless of discipline; and it generates written materials that can be used for both formative and summative assessment of student learning. Figure 1 provides a schematic overview of the process that is described in detail in the following section.

\section{The Development of a Rigorous Reflection Framework}

We have found that structuring reflection mechanisms to include three general phases results in a rigorous reflection framework that maximizes learning and helps to refine reflective skills. These general phases are:

1) Description (objectively) of an experience.

2) Analysis in accordance with relevant categories of learning.

3) Articulation of learning outcomes.

In service-learning, the primary learning objectives can be organized into three categories: academic, personal, and civic. In our reflection framework, based on the work of Kiser (1998), the analysis phase is structured to include consideration of these three areas. When engaged in academic analysis, students examine their experiences in light of specific course concepts, exploring similarities and differences between theory and practice. In analysis from the personal perspective, students consider their feelings, assumptions, strengths, weaknesses, traits, 


\section{Figure 1 \\ Overview of the Process of Articulating Learning as Applied to Service-Learning}

1. Describe service-related experience(s).<smiles>C1CCC2CCCC2C1</smiles>

2. Analyze experience(s) successively from the perspective of each category of servicelearning learning objective:

- Personal

- Civic

- Academic<smiles>C1CC2CCC12</smiles>

3. Identify the core of an important learning in each category.<smiles>C1CCCC1</smiles>

4. Articulate learning by turning this core idea into a well-developed statement of learning —an articulated learning $(A L)$ - using:

- the four guiding questions that structure an $\mathrm{AL}$ as an outline.

- the program-wide service-learning learning objectives to provide guidance/direction in the development of the learning.<smiles>C1CC2CCC1C2</smiles>

5. Apply standards of critical thinking to the draft ALs through:

- Students' self-assessment, and/or

- Reflection leader feedback, and/or

- Instructor feedback.

[Note: Over time, the students improve their ability to apply these standards themselves, before submitting their drafts for review.]<smiles>C1CC2CCC1C2</smiles>

6. Finalize the ALs, aiming to fulfill all learning objectives in each category and meet standards of critical thinking.

[Note: Doing the latter well is generally required for doing the former well.]

7. Undertake new experience(s).

- Including, when feasible, taking action on the goals set/testing the conclusions reached in the ALs.<smiles>C1CC2CCC1C2</smiles>

\section{Continue reflection process outlined here.}

- Including reflecting on the experience of enacting the goals/testing the conclusions reached in the previous ALs, when this has been done, and articulating additional complexity of learning accordingly.

skills, and sense of identity as they are surfaced and sometimes challenged by service-learning experiences. And when examining their service-learning related activities from the civic perspective, students 
explore decisions made and actions taken in light of consequences for the common good, consider alternative approaches and interpretations, identify elements of power and privilege, and analyze options for short-term versus long-term and sustainable change agency. We are currently developing "diversity" as a fourth category in which students identify and analyze the sources and significance of assumptions or interpretations regarding those different from themselves or others and evaluate strategies for maximizing opportunities and minimizing challenges associated with those differences.

In our most rigorous model of reflection, trained undergraduate reflection leaders guide students through these general phases of reflection in small, out-of-class, reflection sessions. However, this same approach of beginning with objective description and then iteratively examining the experience from each perspective can also happen effectively in the context of journal writing or in-class activities. Whatever the forum for reflection, the articulating learning phase brings each reflection activity to a close and establishes a foundation for learners to carry the results of the reflection process forward beyond the immediate experience, improving the quality of future learning and of future experience (related to service or to other aspects of their lives). Therefore, the articulating learning process supports them in recognizing what they have learned through reflection on experience, placing it in context, and expressing it concisely. In other words, it supports them in thinking critically about their own learning.

\section{The Articulated Learning}

The product of this entire process is called an articulated learning (AL). It is structured in accordance with four guiding questions:

1) What did I learn?

2) How, specifically, did I learn it?

3) Why does this learning matter, or why is it significant?

4) In what ways will I use this learning; or what goals shall I set in accordance with what I have learned in order to improve myself, the quality of my learning, or the quality of my future experiences or service?

A complete $\mathrm{AL}$ is a series of paragraphs addressing each of these four prompting questions. It is specific to just one of the categories of learning objectives, such that a single AL articulates an important learning from the academic or the personal or the civic perspective. 
The four questions-similar to the "What? So What? Now What?" model developed by the Campus Opportunity Outreach League and based on Kolb's Experiential Learning Cycle of action and reflection (1984)-embody Dewey's theory that reflection leads to better understanding and more informed action. To complete the learning cycle as described by Kolb, we are going to begin encouraging faculty to implement service-learning such that students are able to take at least one $\mathrm{AL}$ in each category through goal-setting, action on those goals, and reflection on the outcome, resulting in the articulating of new learning.

Analysis of their experiences in accordance with the reflection framework supports students in identifying learning, and the AL process helps them develop and apply or test those learnings in their full complexity. We found, however, that students need more than just the four questions structuring the AL to achieve deep, critical learning. As in the following extreme example, ALs could demonstrate only superficial thinking, such as the learning of a fact:

I learned that the animal shelter is completely dependent on unpredictable donations for support. I learned this when the shelter coordinator told me that's why she couldn't order dog food in large quantities at one time. This matters because it is important to know how organizations like these are funded. I will use this learning in the future by remembering this fact the next time I'm at the animal shelter and I find that it has had to turn away animals because it lacks the food to feed them.

This "learning" also illustrates a circular or obvious explanation of significance ("It is important because it is important to know this") and only limited thinking about how to use or build on the learnings ("I will remember this next time I am in a similar situation").

We wanted to push students to a better awareness and deeper understanding of the issues that they were confronting in their servicelearning experiences. We wanted them to be able to articulate, for example, why the issues are so complex, what factors contribute to or detract from the situation they are experiencing, and the roles that they themselves play as agents of change. In the animal shelter example, we wanted them to compare the approach taken by the coordinator, which was to turn animals away due to insufficient food, to other possible approaches, such as expanding her capacity to take in more animals by finding permanent sources of funding and/or food, identify the reason(s) for her approach, which would require the student seek out this information, and challenges associated with adopting a more sustainable 
alternative, such as trading off time she would rather spend caring for the animals with time spent soliciting continuous support. We also wanted them to consider more systemic dimensions of this civic issue, considering, for example, the role the coordinator or the student might play in ameliorating the fundamental problem of animal abandonment. With this kind of thinking, students can more fully engage with their experiences, maximizing their learning and their ability to serve.

Just as important, we wanted to create a structure whereby the generation of ALs could serve as the final step of reflection in the wide variety of disciplines in which service-learning is being used at our institution-from animal science to political science to civil engineering. Therefore, it had to be easy to adopt and had to be understood by a diverse population of both instructors and students.

\section{Integration of Program-Wide Learning Objectives}

Toward that end, we used questions students address in the second phase (analysis) of our reflection framework as a starting point to create a set of program-level learning objectives (see Appendix A) that can be used in any service-learning-enhanced course in addition to those written by the instructor. They can also serve as a template for more carefully constructing the ALs themselves. In so doing, we were also responding to Eyler's call for "[defined] learning outcomes that would be expected to be enhanced by service participation" (Eyler, 2000, p. 11).

In crafting the specific learning objectives within the academic area, for example, we wanted students to be able to articulate a deepened understanding of the complexities and subtleties of course concepts. However, we realized that prerequisites for such an outcome include recognizing a course concept when they see it at work in their experiences, applying the concept in the context of these experiences, and comparing and contrasting the concept as presented in theory with it as experienced in practice. We also realized that individual students would have differing degrees of achievement in reaching the highest levels of such academic learning, due to differences in their level of cognitive development and in the nature and quality of service-learning implementation in their classes. Accordingly, we decided to present the learning outcomes as a hierarchy within each category (academic, personal, and civic), from the identification of knowledge to a judgment based on critical evaluation. Use of this hierarchical structure supports students in refining their academic learning to the point that they can, for example, make reasoned judgments as to the adequacy of 
a course-related concept relative to their experience. This approach follows the recommendation by Bradley (1997) that written products from service-learning reflection be structured so that they require students to observe, analyze, and evaluate their service experience.

Each learning objective also has a set of questions that carry students through the writing of the ALs and that closely mirror those in the reflection framework, helping to tie together the reflection on learning with the articulation of that learning. It is not necessary for students to follow these in a linear fashion. It is more important that they use these questions as a guide by which to focus and check the process and progress of their thinking.

In the following civic AL, the student identified his group's initial use of an "idealistic" rationale to motivate high school students to engage meaningfully in their own community project (learning objective \#1); considered motivating them by appealing to their desire for good grades as an alternative approach (learning objective \#2); and concluded that that there was value in combining the two approaches in order to achieve both short-term objectives-the students' participation in community service-and a more fundamental change in their attitudes towards such service (learning objective \#3). Throughout the $\mathrm{AL}$, the student struggled with the challenges of working toward a collective goal with individuals who have differing motivations, while also trying to change those motivations (learning objective \#4).

I learned that developing a careful balance between idealistic and selfserving motives amongst group members is essential in meeting collective objectives. There is a danger associated with trading off "ideal" motives for lesser ones (as acceptance of these motives could lead to less beneficial results), although at the same time unmet objectives will likely result from a leader's unwillingness to work with each individual's motives.

I learned this when the [high school students] have thus far been unreceptive to our group's attempts to persuade them that this project should be about the learning and growth they experience (idealistic motives), rather than the grade they receive in combination with the 6.0 GPA score for an [Advanced Placement] class. I do not want to allow the students to settle for just receiving a grade from their projects (and through settling there is a danger that their personal and community results will be less meaningful), yet at the same time I realized even with these perhaps self-serving motives, the [high school] learning community can still receive tangible benefits that will certainly not be met if our group along with [their instructor] refuses to motivate the students with a grade, what currently matters to them.

This learning matters because individuals working together in a group will always have slightly different (and often self-serving) motives for participation in that group, and although a common vision may be somewhat present, there are still discrepancies in each member's idea of an ideal 
end-state. In a leadership role, I must be willing to understand that every member may not be involved for the same reasons: in order to have results instead of inaction I need to be uncompromising in my own ideals, while understanding of the non-idealistic motives for action (such as my need for acceptance or their desire for good grades).

In light of this learning, I will recognize the need to harness motives, both idealistic and more self-serving, for the common good, yet at the same time seek to focus mainly on idealistic motivation to the extent that my group members can handle. Specifically, we may have to use grades as a "carrot" for these [high school students], but through reflection and discussion in the classroom I would like to convince as many of them as possible that this project should not be about the grade, or at the very least not reinforce their idea that grades are their only motivation.

\section{Application of Critical Thinking Principles}

The process that takes a student from observation to evaluation requires the intellectual discipline of critical thinking. As defined by Paul (1993), "Critical Thinking is a systematic way to form and shape one's thinking. ... It is thought that is disciplined, comprehensive, based on intellectual standards, and as a result, well-reasoned" (p. 20). Critical thinking serves as a guide to belief and action and, as outlined by Paul, is based on standards that include accuracy, clarity, relevance, depth, breath, logic, and significance.

In order to facilitate the students' critical thinking, we developed a handout with definitions of the standards along with sample AL passages that exemplify each standard, in order to introduce them to the elements of critical thinking and to support them in trying to integrate each element into their thinking process. For example, the preceding $\mathrm{AL}$ could be strengthened by the addition of supporting evidence for the claim that the students had been unreceptive to the group's efforts and that they care only about grades. Without this information, the accuracy of the student's evaluation of the alternatives cannot be determined and thus the logic of the conclusion can be challenged. In addition, the student could have provided more clarity with respect to his goals (e.g., identification of specific classroom activities or discussion topics), thus better positioning himself to test the validity of his conclusion through action and further reflection.

\section{The Final Product}

Taken together, the learning objectives and critical thinking guide support the reflection process by providing a common language for students and faculty to use to focus and refine the quality of the thinking 
itself and its articulation. Several rounds of feedback, from the instructor, the reflection leader, and/or others students engaged in the same process, informed by these tools, can produce a civic AL such as the following excerpt:

I learned that my role as a servant-leader should consist of being a "stimulator" (someone who rouses activity in other individuals, which later becomes self-sustaining) rather more so than the "facilitator" role (someone who attempts to make progress easier, but is constantly required to continue progress).... Embodying the role of a stimulator can serve to invoke motivation and a sense of empowerment in others whom one stimulates and adds a sustaining component to the progress that is being made with less necessity for continued impulse from the part of the servant leader.

I learned this when comparing the consequences of my actions as a reflection leader for the AP Environmental Science students at the beginning of the semester ... to the role just before and since Spring Break that I have assumed with [a fellow student] in leading them in reflective activities .... At first, we offered suggestions of resources for the students to contact for help with their projects and we offered suggestions on their proposals in order to help them increase the likelihood of receiving funding for their efforts. After a while, we began to perceive little to no significant progress, at least per our expectations, on the part of the students and began to reflect on the fact that they might be seeing us as a crutch for the completion of their project objectives, [as evidenced by] their poor level of conversation about proposals and their lack of confidence in the direction of their projects [by] asking us what they [should] do.... After leading reflection sessions during class, we have found that our methods-creating provocative activities and framing questions around them-have really invoked deeper thinking in the students [as] gauged by ... [the] significant amount of breadth, depth, and integration in their responses to the questions and in their articulated learnings. This continued process has really engaged the students in being more self-critical and has caused them to really evaluate their progress ... more between our visits, as [their teacher] has told us....

This learning matters because taking on a role as a "stimulator"... can help other individuals to begin holding themselves accountable ... in completing the tasks that are needed to work toward inducing significant change.... While making the project easier through a facilitative role may be necessary given certain circumstances, providing a stimulus to act can be more permanent and multiply the creativity and sense of empowerment, and therefore productivity and progress of members of a group acting to induce change. The challenge arrives when those whom the stimulator is targeting resist the change that is inherent in the power that they are given.

In light of this learning, I will work together with other members of my group to develop our methods and integrate new ones for becoming stimulatory agents and determining when a facilitative or stimulatory role is more necessary during the coming month in which our work with the ... project will conclude. Preliminarily, we are looking to have another type of reflective session with each class next week for them to evaluate 


\section{Table I \\ Example of Level 4 (of 4) of the Critical Thinking Rubric for Assessing Articulating Learnings}

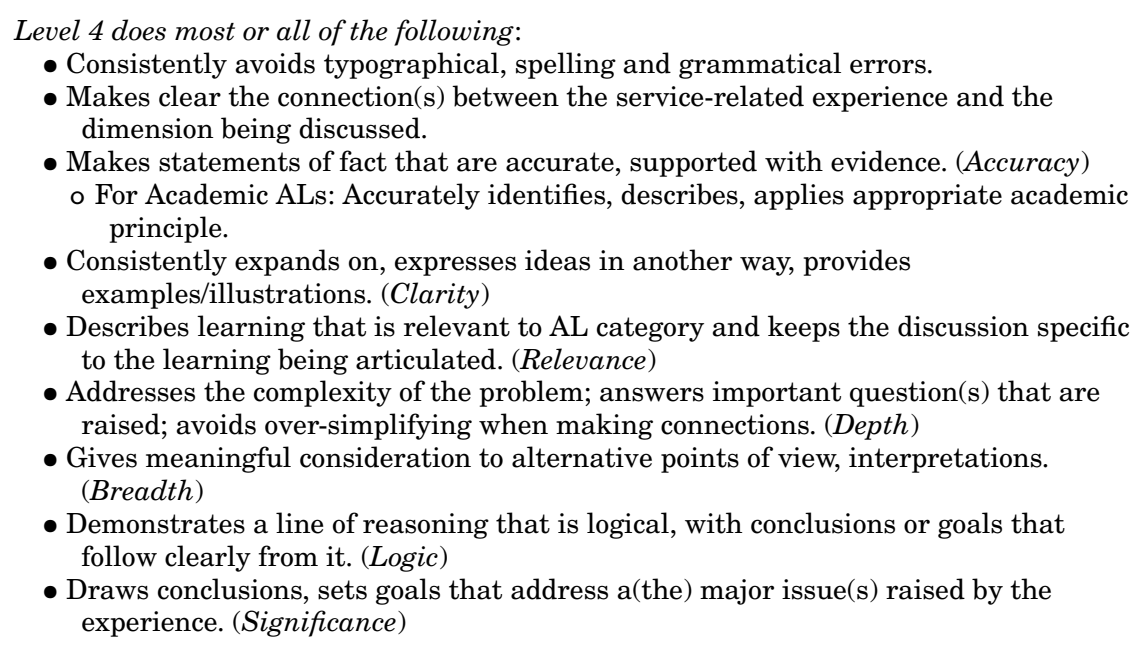

their progress, redefine some of their own goals as necessary, and raise sustainability issues for their projects....

\section{Use of Written Reflection Products for Assessment Purposes}

The preceding AL reflects the formative use of the learning objectives and the critical thinking guide to help students organize, frame, and check the quality of their thinking as they write their ALs. However, the ALs can be used for summative assessment as well. First, an AL can be evaluated with respect to the highest level learning objective it meets. Second, the critical thinking standards can be applied to the ALs in the form of a holistic rubric (see Table I) that we have adapted from Paul's critical thinking standards. The rubric describes four levels of mastery relative to these standards that have been written with specific reference to learning based on a service-related experience. Overall, our approach has some of the same general features as the $A B C$ template developed by Welch (1999), which evaluates student journal entries based on the presence of affective, behavioral, and cognitive components. However, the AL process described here provides more support for the writing of the reflection product itself by structuring it around specific learning objectives and explicitly incorporating the standards 
of critical thinking. This process also allows for the assessment of the quality of the thinking.

Instructors can use the information provided by the learning objective and critical thinking assessment strategies in a variety of ways. For example, the level of student mastery relative to the learning objectives and critical thinking rubric for a particular course concept provides valuable feedback on their teaching by identifying those concepts that appear harder for students to grasp. Possible sources of confusion may become particularly apparent when reading students' attempts to apply the concept to their experiences. Although articulated learnings are not meant to replace all other student learning products in a course, instructors may also find these tools useful for quantifying the reflective or service-learning component of the students' final grades. This helps to fulfill the principle of experiential education, often challenging, that credit be given not for the experience itself but for learning achieved through reflection on that experience (Walker, 1990).

More generally, because the articulated learning process provides evidence of student learning outcomes, it can help meet the growing demand for accountability in higher education, which requires instructors, departments, programs, and institutions to identify and demonstrate the knowledge, skills, and competencies they want students to have as a result of their educational experience. It allows for assessment that grows out of and is customized to the particular learning objectives in question. Because the articulated learning is a course-embedded process, it is less time-consuming for both students and instructors than interview, focus group, or portfolio methods used or recommended by others (Eyler \& Giles, 1999; Gelmon, S.B., Holland, B.A., Driscoll, A., Spring, A, \& Kerrigan, S., 2001; Serow, R.C., 1997); and it provides more substantive information than surveys and inventories alone (Gelmon, S.B., Holland, B.A., Driscoll, A., Spring, A, \& Kerrigan, S., 2001; Payne, 1993).

\section{Additional Applications}

\section{As a Research Tool}

We are currently using the ALs and their associated assessment strategy to answer a variety of research questions. For example, how much improvement can students make over the course of the semester in articulating their learning in each of the categories of learning objectives? Are they more likely to make progress in writing in one category 
as compared to another, and what might be the reasons for such differences? How might attainment of learning outcomes vary with type of service (e.g., one-time versus multiple experiences), reflection process (e.g., reflection sessions versus journal writing only), students' educational level (e.g., freshman versus senior), and discipline (e.g., technical versus humanities)?

We are also looking at the relationship between the learning objectives and the critical thinking rubric to help us better understand and refine both. For example, how can we use the standards of critical thinking to help improve students' ability to master each level of the learning objectives? And are there ways to improve the wording of the learning objectives to provide better support for the students' critical thinking? Finally, we are interested in comparing this model to other assessment strategies such as King and Kitchener's (1994) Reflective Judgment Model, which evaluates student writing relative to levels of intellectual development.

\section{As a Faculty Development Tool}

Supporting student reflection both requires and nurtures reflective practice on the part of faculty. Our service-learning program offers workshops on the approach to reflection and assessment described here, and beginning next year we will provide a virtual tutorial on articulating learning for faculty as well as students. Beyond learning to use these tools in support of student reflection, however, we also encourage service-learning faculty to use this process to support their own reflection and subsequent personal and professional development. Our goal is to have them regularly reflect on their teaching experiences, articulate specific "lessons learned" in the process, and share that learning with their students and each other-an outcome that we believe will substantially improve the function of this group of instructors as a learning community. Articulating learning clearly supports our attempts to grow as the "reflective practitioners," of whom Schön speaks, by helping us to understand better the choices we make in the classroom and the assumptions we hold about our students. It also increases our ability to integrate critical thinking principles throughout our teaching as we craft assignments, explain objectives, and consult with students. Finally, it better positions us to support them in the challenge of learning to learn through reflection. As we share our own ALs, we model disciplined reflection, appropriately full of ambiguity and internal tensions. We find that students come to take the process more seriously and to 
respect and reciprocate our willingness to be vulnerable and receptive to feedback from other perspectives that such sharing implies. Thus, our professional development as faculty is intimately linked with the development of our students.

\section{Future Directions}

Eyler, Giles, and Schmiede (1996) noted that reflection "need not be a difficult process, but it does need to be a purposeful and strategic process" (p. 16). This conviction has been at the heart of our efforts to develop a rigorous, adaptable, learner-centered approach that both challenges and supports students in learning through reflection on experience. Our understanding of how to do this well has clearly evolved and will continue to do so, in large part through our own reflective practice. Refinements of the AL process have been guided primarily by the patterns (both positive and problematic) we have found in the ALs themselves and in student feedback. This iterative process will continue in the future as we support faculty and students in using the articulated learning in an increasing array of curricula and institutional settings. In addition, we will be experimenting with ALs as the culminating step of individual guided journal-writing and in-class reflection activities, and we will be using the learning objectives themselves as a stand-alone tool for guiding reflection in the absence of instructor or reflection leader facilitation.

Our experience suggests that positioning articulating learning at the heart of guided reflection-in virtually any learning situationminimizes the risk, identified by T.S. Eliot (1943), that one might have "had the experience but missed the meaning" (p. 24). And, indeed, it maximizes the unique potential of experiential education to nurture learning in its full richness and complexity.

\section{Acknowledgments}

The reflection framework was originally developed by undergraduates Nick Haltom and Gretchen Lindner, along with Patti Clayton. The four-part structure for articulating learning was developed by undergraduate Jason Grissom. The authors wish to acknowledge Barbi Honeycutt, Virginia Lee, Mary Catherine Brake, Julie David and Myra Day for their assistance in developing the assessment portion of this process. 


\section{References}

Bloom, B. S. (Ed.). (1956). Taxonomy of educational objectives, handbook I: Cognitive domain. New York, NY: David McKay Company.

Bradley, L. R. (1997). Evaluating service-learning: Toward a new paradigm. In A. S. Waterman (Ed.), Service-Learning: Applications from the research (pp. 151-171). Mahwah, NJ: Erlbaum.

Conrad, D., \& Hedin, D. (1990). Learning from service: Experience is the best teacherOr is it? In Jane Kendall and Associates (Eds.), Combining service and learning. I (pp. 87-98). Raleigh, NC: National Society for Internships and Experiential Education.

Dewey, J. (1910). How we think. Boston, MA: D.C. Heath and Company.

Eliot, T. S. (1943). The four quartets. New York, NY: Harcourt, Brace, and Company.

Eyler, J. (2000). What do we most need to know about the impact of service-learning on student learning? Michigan Journal of Community Service Learning, Special Issue Fall, 11-17.

Eyler, J., \& Giles, D. E. (1999). Where's the learning in service-learning?. San Francisco, CA: Jossey-Bass.

Eyler, J., Giles, D. E., \& Schmiede, A. (1996). A practitioner's guide to reflection in servicelearning. Nashville, TN: Vanderbilt University.

Gelmon, S. B., Holland, B. A., Driscoll, A., Spring, A., \& Kerrigan, S. (2001). Assessing service-learning and civic engagement. Providence, RI: Campus Compact.

Hondagneu-Sotelo, P., \& Raskoff, S. (1994). Community service-learning: Promises and problems. Teaching Sociology, 22, 248-254.

Kiser, P. M. (1998). The Integrative Processing Model: A framework for learning in the field experience. Human Service Education, 18, 3-13.

King, P. M., \& Kitchener, K. S. (1994). Developing reflective judgment: Understanding and promoting intellectual growth and critical thinking in adolescents and adults. San Francisco, CA: Jossey-Bass.

Kolb, D. (1984). Experiential learning. Englewood Cliffs, NJ: Prentice Hall.

Payne, C. A. (1993). Construction of an instrument to assess the service learning model: Establishing concurrent validity and internal reliability. (Doctoral dissertation, University of Northern Colorado, 1992). Dissertation Abstracts International, 53 / 07A.

Paul, R. (1993). Critical thinking: What every person needs to survive in a rapidly changing world. Santa Rosa, CA: Foundation for Critical Thinking.

Rogers, R. (2001). Reflection in higher education: A concept analysis. Innovative Higher Education, 26, 37-57.

Schön, D. (1983).The reflective practitioner: How professionals think in action. New York, NY: Basic Books.

Serow, R. C. (1997). Research and evaluation on service-learning. In A. S. Waterman (Ed.), Service-Learning: Applications from the research (pp. 13-24). Mahwah, NJ: Erlbaum.

Stanton, T. K. (1990). Liberal arts, experiential learning and public service: Necessary ingredients for socially responsible undergraduate education. In Jane Kendall and Associates (Eds.), Combining service and learning I (pp. 175-189). Raleigh, NC: National Society for Internships and Experiential Education.

Steinke, P., \& Buresh, S. (2002). Cognitive outcomes of service-learning: Reviewing the past and glimpsing the future. Michigan Journal of Community Service Learning, 8, $5-14$.

Strand, K. J. (1999). Sociology and service-learning: A critical look. In J. Ostrow, G. Hesser, \& S. Enos (Eds.), Cultivating the Sociological Imagination. (pp. 29-37). New York, NY: American Association for Higher Education.

Walker, U. (1990). Assessing Learning. In Jane Kendall and Associates (Eds.), Combining service and learning II (pp. 206-207). Raleigh, NC: National Society for Internships and Experiential Education. 
Welch, M. (1999). The ABCs of reflection: A template for students and instructors to implement written reflection in service-learning. NSEE Quarterly, 25, 22-25.

\section{Appendix A: Service-Learning Program-Wide Learning Objectives}

Academic Dimension

1) Identify and describe course concepts in the context of your servicelearning related activities.

- Describe the course concept that relates to your service-learning experience.

-AND-

- Describe what happened in the experience that relates to that course concept.

2) Apply course concepts in the context of these activities.

- How does the concept help you to better understand, or deal with, issues related to your service-learning experience? -AND/OR-

- How does the service-learning related experience help you to better understand the course concept?

3) Analyze course concepts in light of what you have experienced in these activities.

- In what specific ways are the concept (or your prior understanding of it) and the experience the same and/or different? -AND-

- What complexities do you see now in the concept that you had not been aware of before?

-AND/OR-

- What additional questions need to be answered or evidence gathered in order to judge the adequacy/accuracy/appropriateness of the concept when applied to the experience?

4) Synthesize and evaluate course concepts in light of what you have experienced in your service-learning related activities.

- Based on the analysis above, does the concept (or your prior understanding of it) need to be revised and if so, in what specific ways? Provide evidence for your conclusion. -AND- 
- If revision is necessary, what factors do you think have contributed to the inadequacy in the concept as presented or in your prior understanding of it? (E.g., bias/assumptions/agendas/lack of information on the part of the author/scientist or on your part.) -AND-

- Based on the analysis above, what will/might you do differently in your service-learning or other academic-related activities in the future?

-OR-

- Based on the analysis above, what should/might your service organization do differently in the future and what are the challenges that it night face as it does so?

Personal Dimension ${ }^{1}$

1) Identify and describe an awareness about a personal characteristic that has been enhanced by reflection on your service-learning related activities.

2) Apply this awareness in the context of your service-learning related activities and to other areas of your life now or in the future.

3) Analyze the sources of this characteristic and the steps necessary to use or improve on it in your service-learning related activities and other areas of your life.

4) Develop and evaluate your strategies for personal growth.

\section{Civic Dimension}

1) Identify and describe an approach (e.g., decision or action) you or others took or, looking back on it, could have taken.

2) Apply your understanding of your (others') approach in processes of collective action to the relationship between social action and social change.

3) Analyze the appropriateness of the approach taken and the steps necessary to make any needed improvements in the approach.

4) Evaluate your (others') role as an agent(s) of systemic change.

${ }^{1}$ The complete list for the Personal and Civic categories are available by contacting the authors at sarah_ash@ncsu.edu. 
Copyright of Innovative Higher Education is the property of Kluwer Academic Publishing and its content may not be copied or emailed to multiple sites or posted to a listserv without the copyright holder's express written permission. However, users may print, download, or email articles for individual use. 